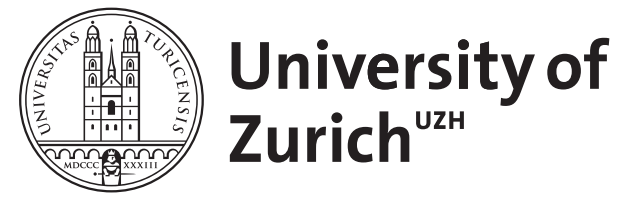

Zurich Open Repository and Archive

University of Zurich

University Library

Strickhofstrasse 39

CH-8057 Zurich

www.zora.uzh.ch

Year: 2011

\title{
Quantitative and Qualitative Rankings of Scholars
}

Frey, Bruno S ; Rost, Katja

Posted at the Zurich Open Repository and Archive, University of Zurich ZORA URL: https://doi.org/10.5167/uzh-55840

Journal Article

Published Version

Originally published at:

Frey, Bruno S; Rost, Katja (2011). Quantitative and Qualitative Rankings of Scholars. Schmalenbach Business Review (sbr), 63(1):61-89. 


\title{
Quantitative and Qualitative Rankings of SCHOLARS
}

\begin{abstract}
In a former article we started to argue that publication and citation rankings of individual scholars do not effectively measure research quality, which should in fact be the essence of evaluation (Frey and Rost (2010)). For the field of economics we show that an alternative ranking based on membership on academic editorial boards of professional journals is randomly correlated with citation and publication rankings of these scholars. In this article we go a step further by hypothesizing a systematic, inverted $U$-shaped relationship between quantitative and qualitative rankings. By relying on a longitudinal data set of management scholars who are part of the international topcommunity in organization science the findings support this multi-tasking effect. While a certain amount of publications indeed reflects aspects of research quality, it also suggests that maximizing publications ignores other essential aspects of research quality that are doubtlessly hard to measure. It follows that if career decisions are only based on high scores in publication rankings the result will be not only haphazard but may be even counterproductive for science.
\end{abstract}

JEL-Classification: H43, L15, O38.

Keywords: Evaluations; Rankings; Research Quality; Scholars; Universities.

* Katja Rost, University of Mannheim, Economic and Organizational Sociology, Parkring 47, D-68159 Mannheim, Germany, phone: +49621 181-3942, fax: +49 621 181-1983. Bruno S. Frey, University of Zurich, Institute for Empirical Research in Economics, Winterthurerstrasse 30, CH-8006 Zurich, Switzerland, phone: +41 44 634-3731, fax: +41 44 634-3599, and CREMA - Center for Research in Economics, Management and the Arts, Switzerland.

** The authors are grateful for the helpful comments by three reviewers of the sbr, by the editor of the sbr, and by Margit Osterloh. We further thank all peers who discussed with us the advantages and disadvantages of scholar rankings, in particular Christine Benesch, Axel Dreher, Reiner Eichenberger, Thomas Ehrmann, Axel Franzen, Jetta Frost, Martin Gassebner, Fabian Homberg, Emil Inauen, Alfred Kieser, Christopher Lettl, Roger Luethi, Simon Lüchinger, William McKinley, Andreas Scherer, Alois Stutzer, Gerhard Speckbacher, Till Talaulicar, Antoinette Weibel. 


\section{INTRODUCTION}

Rankings in terms of the number of publications and citations are a popular method of examining and mapping the intellectual impact of scientists, projects, journals, disciplines, faculties, universities, and nations (Garfield (1979); Borgman (1990); Moed (2005); Judge et al. (2007); Meho (2007); Cronin and Meho (2008); Fabel, Hein, and Hofmeister (2008); Handelsblatt (2009)). Rankings are commonly used worldwide for policymaking, to monitor scientific developments, and to serve as a basis for promotions, tenure, hiring, salary, and grants decisions (Cronin (1996); White and McCain (1998); Small (1999); Warner (2000); Borgman and Furner (2002); Weingart (2005)).

In a former article we started to argue that rankings are quantitative; they indicate the position, or rather the significance, of a scholar, university, or country relative to others (Frey, Rost (2010)). It is however quality that should be considered the essence of scientific research rankings (e.g., Johnes (1988)); society does not benefit from how many publications have been authored, and how many citations have been accumulated. What should matter is the advancement of new insights and their value (Adler and Harzing (2009)), i.e., whether the research is useful, satisfies stated or implied needs, is free of deficiencies, and meets more general social requirements (see, e.g., Reedijk (1998); Nightingale and Scott (2007)) $)^{1}$.

In order to demonstrate that quantitative rankings measure research quality only to a limited extent we compared rankings, which are based on publications and citations, with rankings, which are based on membership in the scientific boards of academic journals (Frey and Rost (2010)). Editor board rankings consider the reputation and recognition of scholars among their peers. Scholarly reputation depends on a great many factors, but the qualitative aspect is certainly central. (We note that quantitative and qualitative rankings are not strictly separable as both contain elements of the other. The distinction is made solely for clarity). A major result of this study is that quantitative and qualitative rankings of individual scholars are randomly correlated with each other. The same conclusion does, however, not hold for more aggregated levels of analysis, in particular for the comparison of countries.

In this article we therefore concentrate on individual scholars and analyse the relationship between quantitative and qualitative rankings in more detail. In our theory we rely on the multi-tasking and the creativity literature in order to hypothesize that both rankings are inverted U-shaped related to each other. In order to test this relationship we collect suitable data on management scholars. In contrast to our first empirical study, the sample compares scholars of one sub-community and not of many sub-communities ensuring similar publication, citation, and editor membership habits. This community has an extraordinary high international reputation securing that the dataset is representative

1 Efforts have been made to include quality aspects in rankings, for example by counting only those publications and citations that appear in scientific journals of "acceptable" quality or by considering "impact" factors that consider the ranking of a journal in which a publication or citation appears. Nevertheless, the resulting rankings take the quality aspects of research activity into account only to a limited extent. 
for the elite. We predict the relationship between quantitative and qualitative rankings by controlling for a diverse set of indicators and by running robustness test, e.g. by using corrected measurements of publication records which are sometimes suggested to overcome the problems of current rankings.

A significant result of our empirical study is that quantitative and qualitative rankings are not linearly related to each other. Instead, the number of publications shows an inverted U-shaped relation to scholars who are selected as board members. This suggests that persons who score high in publication rankings will score only modestly in our alternative ranking. For this reason, high scores in publication rankings should not become the only goal of research evaluation. Publication rankings ignore features that are difficult to measure (Holmström and Milgrom (1991)). In the long run they may be even counterproductive by crowding-out scholar contributions which are hard to measure but still important for research quality. We do not claim that the ranking based on editorial board membership that we develop here is a better ranking method. However, we do argue that publication rankings disregard other, important scholarly contributions.

The paper is organized as follows. Section 2 gives a short overview of the rankings currently in use, based on publications and citations, and identifies their shortcomings. We discuss how, and to what extent, quality is captured by an alternative definition of scientific worth, membership on editorial boards. Both sub-sections are a short repetition of our first article on rankings. Following, we develop the hypothesis to be tested in this study: quantitative and qualitative rankings are expected to be inverted U-shaped related to each other. In Section 3 we present the empirical results for our sample of 5,794 researchers who published their research in at least one of 11 international top journals of the management and organization research community in the period from 1997-2007. In $2009,1,316$ scholars held at least one editor, co-editor, or board position in these journals. In Section 4 we argue that due to the substantial instability of scientific rankings, more care should be taken when using rankings for decision-making, in particular when making decisions about the careers of individual scholars. We present four alternatives to quantitative rankings and shortly point out some advantages and disadvantages.

\section{Current Scientific Rankings}

\subsection{Quantitative Rankings}

Evaluating scientific quality is notoriously difficult (Cherchye and Vanden (2005)). Ideally, established experts in the field should scrutinize the published scientific results. However, in practice, committees comprised of members with general competence, rather than specialists often evaluate primary research data. In the past, these committees used peer review and other expert judgments until claims were made that expert judgments could be biased, and therefore could be inferior to seemingly objective measures, such as the number of publications and citations (Horrobin (1990); Moxham 
and Anderson (1992)) ${ }^{2}$. Today, these committees tend to use secondary criteria ${ }^{3}$, so it is hardly surprising that the prevalent ranking principle for evaluating research focuses on quantity, which appears to be an objective indicator directly related to published science (Adler, Ewing, and Taylor (2008)).

Such bibliometric indicators have several advantages. First, the data are easily available, for example, from publication lists or other data sources such as the Web of Science. Second, bibliometric counts seem to be objective indicators. Third, bibliometric indicators facilitate the comparison between a large number of candidates or institutions.

Bibliometric indicators have, however, also disadvantages. Disadvantages in particular arise due to the effort to capture a qualitative aspect in the current rankings. First, most rankings ignore publications such as books, general public notices, handbooks, and other collections of articles, as well as anything published in a non-refereed journal (Johnes (1988); Reedijk (1998); Donovan and Butler (2007); Adler and Harzing (2009)). Second, publications in refereed journals are categorized according to the prominence of the journal measured by impact factors ${ }^{4}$. However, journal impact factors ignore the fact that the citation rates of an article determine the impact factor of a journal, but that the reverse is not true (Seglen (1997)) $)^{5}$. Third, the obscure weighting of journals according to their prominence often coincides with a remarkable incompleteness of the database (Adler and Harzing (2009); Albers (2009)). It is hardly surprising that the ranking positions of scholars depend on the precise execution of the rankings (Coupé (2003); Meho and Rogers (2008)).

In order to overcome these limitations it has been suggested to consider citation records (e.g., Nederhof and van Raan (1993)). The underlying assumption is that citations show that the individual, the journal, the institute, or the country cited has performed work that is relevant to current research frontiers and is useful to those attempting to extend those frontiers (Diamond (1986)). However, to the extent that citations inadequately account for scientific quality, the corresponding rankings distort the informative function they claim to provide. The use of citations as an indicator of scientific quality reveals six major shortcomings:

2 The opinions of experts may indeed be influenced by subjective elements, narrow-mindedness, and limited cognitive horizons. These shortcomings may result in conflicts of interest, unawareness of quality, or even a negative bias against young scientists or newcomers to a particular field.

3 Rigby and Edler (2005) analyzed the degree to which the bibliometric information of 169 research groups in economics, econometrics, and business administration relates to the assessment results of three evaluation committees. More than half of the variation in the overall quality judgments of the committees can be predicted by using a handful of bibliometric variables, notably the number of publications in top-ranked and international refereed journals, the number of international proceedings, and the number of Dutch journal articles.

4 Many journal rankings according to citations have been undertaken (e.g., Liebowitz and Palmer (1984); Diamond (1989); Laband and Piette (1994); Cheng, Holsapple, and Lee (1995); Hennig-Thurau, Welsh, and Schrader (2004); Paul (2004); Sombatsompop, Markpin, and Premkamolnetr (2004); Podsakoff et al. (2005); Handelsblatt (2009); Schrader and Hennig-Thurau (2009)).

5 Seglen (1994) shows that $15 \%$ of the articles account for $50 \%$ of the impact factor of a journal. Other research notes that many top articles are published in lower-ranked journals, and many average articles are published in higher-ranked journals (Singh, Haddad, and Chow (2007); Adler and Harzing (2009)). 
- First, citations do not consider whether a scholar's contribution is valuable and furthers the course of scientific knowledge, is neutral, or hinders scientific progress ${ }^{6}$.

- Second, scholars are human beings and follow fashionable trends or herding behavior (Banerjee (1992); Bikhchandani, Hirshleifer, and Welch (1992); Chamley and Gale $(1994))^{7}$. This "Matthew Effect" in science (Merton (1968)) leads to the emergence of "star" papers and authors whose only claim to fame is that they are famous, but few people actually know or care about how the stars got to be famous (Barabási and Albert (1999); Bonitz, Bruckner, and Scharnhorst (1999); Faria (2005); Baccini and Barabesi (2008) $)^{8}$.

- Third, the fact that a particular work has been cited does not mean that it has been read (Donovan (2006)) 9 .

- Fourth, citation counts do not indicate quality independent of the "contested" knowledge (Beed and Beed (1996)) ${ }^{10}$.

- Fifth, it is widely accepted as a best practice in the bibliometric community that it is preferable not to apply publication and citation measures to individuals, but instead to use higher levels of aggregation, in particular, to universities or countries (van Raan $(2003))^{11}$.

6 The latter happens if the scholar promotes an unproductive or even unsound approach, theory, method, or result. If qualitative aspects were taken seriously, unproductive citations would be given a zero rating and counterproductive citations would weigh negatively.

7 We see this influence when scholars quote papers simply because they have previously been cited by other researchers. Simkin and Roychowdhury $(2005 ; 2006 ; 2007)$ show that the probability of a scholar being cited is affected by the number of citations he or she already has.

8 In the case of celebrities, the "Matthew Effect" is of little relevance, since their main objective is to entertain. However, in science, where a commitment to the search for knowledge and understanding is so important, such citations should be put into a different category; they should not count as positive contributions.

9 Although no scholar would be foolish enough to publicly admit that he or she cited articles without having read them, there is now empirical evidence that this lacuna does occur to a significant extent. Evidence that an academic has not read the cited article can be found in the identical misprints that appear repeatedly in citations. Such misprints are most likely to occur when authors copy reference lists contained in others' papers. Based on a statistical analysis, Simkin and Roychowdhury (2005) conclude that about $70 \%$ to $90 \%$ of scientific citations are copied from the lists of references used in other papers. This result does not automatically imply that all citations copied from reference lists are not read, but it is an indication that some papers cited have not been read by those who are citing them.

10 In competitive disciplines, such as management or other social sciences, different citation counts indicate which author, article, or journal embraces the dominant theory most completely and which does not (Lee (2006)). Many scholars assume that articles that embrace unfamiliar reasoning and arguments have unimportant content. Therefore, these articles are rarely cited. Thus, differences in citation rankings often reflect the subjective or ideological rejection of the theory used rather than the quality or importance of the research to the discipline. Consequently, in departments or universities where tenure, promotions, salaries, and department funding are affected by citation rankings, controversial findings, which are mostly published in less prestigious journals, are penalized (Coats (1971); Bell and Seater (1978); Bräuninger and Haucap (2003); Lee (2006)). Therefore, evaluations that rely on citation counts crowd out the crucially important innovative research in the social sciences. Such evaluations encourage a detrimental homogeneity in science, as has been shown for business schools (Gioia and Corley (2002)).

11 Bibliometric scientists argue that although these indicators may make sense in the natural and life sciences, such indicators are problematic in the social and behavioral sciences where journals play a lesser role as primary communication channels. Many research fields are locally oriented, and older studies are more dominant (van Raan (2003)). 
- Sixth, the list of shortcomings could easily be extended to include the different citation habits of authors in different fields and subfields, the selectivity of citations by authors (e.g., easily available papers are cited more often), unintended spelling errors by authors in citation lists, mistakes in counting and classifying citations and accrediting them to journals and authors, and the inclusion of self-citations (especially by determining the journal impact factor) ${ }^{12}$.

In fact, these restrictions are often ignored (see, for example, the ranking attempts of German business scholars or economists by Bommer and Ursprung (1998); Handelsblatt (2006; 2007); Fabel, Hein, and Hofmeister (2008); Handelsblatt (2009)) ${ }^{13}$. The benefit of such proceedings is doubtful and may negatively affect the quality of the social sciences. Because of all the shortcomings that are involved in using citations as reliable indicators of scientific quality, there is good reason to consider alternative approaches.

\subsection{Qualitative Rankings}

A defining characteristic of any science is that its participants consider themselves members of a community of scholars (Lee (2006) $)^{14}$. Thus, for scientists to be embedded in a research community is a quality indicator of research. It ensures that the scientists and their research meet research standards accepted by their scientific community, for example, by utilizing proven research techniques. Professional scientific journals are the publication outlets for different research communities. In this respect, the editorial boards constitute the true experts in the research community, and being appointed an editorial board member is not only a great honor, but is also indicator of scientific quality (Kaufman (1984)).

The board fulfils two different functions: First, it assists the editors in choosing the most suitable articles for the respective scientific field. Second, it reflects the individual's standing in the profession as evaluated by his or her peers. However, when board members contribute to editorial decisions and even when they are mainly, or only, honorary members,

12 Some editors freely admit that they encourage authors to cite as many publications in their journal as possible in order to raise their impact factor (Garfield (1997)).

13 Even though the Handelsblatt Ranking is more accepted in economics, it has spread rapidly in the field of business administration and has become accepted. For example, some German business scholars documented their ranking position on their homepages, faculties published their rankings in newspapers, or appointments committees nowadays use the Handelsblatt Ranking to compare the publication lists of applicants in the field of business administration.

14 Scientific knowledge is not some immutable objective stock that grows quantitatively; rather, it is fallible, historically contingent, it can be challenged, and it can change unpredictably and qualitatively. This competition is especially true for the social sciences. What constitutes scientific knowledge depends on the approval by the scientific community 
the choice of members should be based on quality ${ }^{15}$. A (chief) editor wants to have scholars at hand who can help him or her make the best possible decisions; a less reputable individual or a person lacking expert knowledge is of little use. At the same time, because the scholars represented on boards have excellent professional reputations, membership on boards can be a reasonable approximation of the quality of an academic as judged by his or her peers ${ }^{16}$. Gibbons and Fish ((1991)) take it as a matter of course: "Certainly, the more editorial boards an (scholar) is on, the more prestigious the (scholar)."

However, we note that using editorial board positions as a quality indicator also has disadvantages. First, it clearly favors established scholars. But using the number of publications and citations has the same disadvantage. Second, only a small fraction of all scholars are members of editorial boards. This fact distorts the results because it includes only the best scientists. However, management scholars in many countries have their own journals. Within these journals, the countrywide experts in a field are members of editorial boards. Although our research relies mainly on scholars who enjoy an international reputation, research evaluation could also include journals that originate in a specific country, e.g., in Austria, Germany, and Switzerland, we have sbr/ZfbF, Die Betriebswirtschaft, Die Management Revue, Das Journal für Betriebswirtschaft, Die Unternehmung, Zeitschrift für Betriebswirtschaft, Zeitschrift Führung und Organisation, or Review of Managerial Science. Third, some scholars may be elected to an editorial board simply because they are well known, regardless of the fact that they are no longer productive. Although this argument may be true, it would be wrong to conclude that these scholars have no research quality.

\subsection{Relation between Quantitative and Qualitative Rankings}

Measured by quantitative rankings, the publication record of a scholar can be (but does not necessarily need to be) positively correlated with his or her engagement in multiple other tasks (Frey (2010)). In addition to doing research and having their research favorably published, the main tasks of scholars are teaching, supporting young scholars, informing and advising the public, participating in university administration, or reading and reviewing the work of other scholars. Thus, for the following reasons it is likely that there is a negative correlation between publishing and the previously mentioned tasks:

- First, because of time and effort constraints, few scholars are able to perform these tasks sufficiently well and still fully engage in the arduous task of publishing research papers.

15 For example, honorary members are often chosen to signal the orientation of the review (e.g., whether its emphasis is on theoretical or empirical work). More importantly, journals want to profit from the reputation of honorary board members (Kaufman (1984)). The more distinguished these members are within their discipline and community, the higher is the journal's reputation, because renowned scholars do not join the boards of poorquality journals. (Were they to do so, their own reputation would decline.)

16 This procedure has been put forward in the past and undertaken for small, distinct sets of journals by Kaufman ((1984)) for finance faculties, Kurtz and Boone (1988) for marketing faculties, and Gibbons (1990) for statistics faculties. 
- Second, a publishing record is easy to measure, but performance on the other tasks is not. The multiple-task effect (Holmström and Milgrom (1991); Prendergast (1999)) suggests that academics mainly engage in publishing efforts and ignore the other tasks ${ }^{17}$.

- Third, the distribution of talent among those scholars who are able to publish in the highest-ranked journals and those who are not, is likely to overlap. It follows that the worst scholars whose papers appear in top publications are less capable of excelling in the other tasks (they are the so-called "lemons") than are the best scholars who are not published in A-level publications.

- Fourth, writing articles for A-level journals is a highly specialized activity (Starbuck (2009)). Scientists who perform well in the specialized activity of writing articles for A-level journals may perform only modestly in the other six tasks.

Thus, we expect that the position of a scholar in quantitative rankings, i.e., his or her number of publications, is not strictly related linearly to his or her position in our qualitative rankings, i.e., using editorial board positions as a quality indicator. We argue that up to a point, the position of a scholar in quantitative rankings is only linearly related to his or her position in qualitative rankings. Beyond this point, there is less benefit realized from a higher number of publications, and it may constrain the position of a scholar in qualitative rankings (Frey (2007)). In theory, U-shaped relations are common for innovative or creative activities in which there is the possibility of multiple outcomes (PerrySmith and Shalley (2003)).

On the one hand, editorial board members may need a minimum number of publications. Scholars who are able to continuously publish their research in reputable journals not only show a high level of research motivation, but also talent (Cole (1992)). Having such scholars on the editorial board signals research quality and thus improves the number and quality of submissions to a journal. Second, effort and expert knowledge are important to fulfill the tasks within editorial boards, e.g., to distinguish between good and excellent research, to identify errors, to evaluate the trustworthiness of research, or to responsibly fulfill assignments within short time periods.

On the other hand, a scholar who may represent an excellent choice as editorial board member might not have a large number of publications. Being visible as a possible editorial board member requires additional task investments, all of which reduce the time for publishing. In theory, this effect has been labeled multitasking effect. For complex problems consisting of multiple tasks, such as research, it means that people can or will concentrate only on certain tasks and will neglect everything else (Holmström and Milgrom (1991)).

17 Multiple tasking effects can also affect publication strategies (Adler and Harzing (2009); Osterloh and Frey (2009)). To receive high scores in publication and citation rankings may become an academic's goal, rather than to examine and determine how and why the conducted research may be important. There are many examples for these tactics, such as the "slicing strategy" (Butler (2003)), i.e. the maximization of publications by dividing research into small publishable units; the "academic prostitution" strategy (Frey (2003)), i.e., the voluntary distortion of research results; the inclusion of wasteful citations; the adding of famous, albeit imaginary, co-authors that enable a junior researcher to survive review processes; or the "mediocrity" strategy (Osterloh and Frey (2009)), i.e., the decision to conduct uncreative, orthodox research to please the average referee and thus to increase the likelihood of publication. 
First, scholars who are visible as possible editorial board members must be good reviewers. Being a good reviewer can be positively correlated with the number of publications. Reviewing involves spending valuable time on the work of other scholars and wide reading. Reviewing and reading reduces the time for writing and publishing. According to the multitasking theory, it seems likely that many scholars may be quietly productive in either reviewing or publishing, but only few scholars will be active in both areas.

Second, to motivate the research community to submit their publications, scholars who are possible editorial board members should be associated with outstanding research content. Outstanding research might be positively correlated with the number of publications. Producing meaningful and innovative research content is often slower than producing rigorous but less meaningful, "standard" research content. Further, the acceptance of innovative research is far from certain (Dasgupta and David (1994); Nelson (2004)). Again, it seems likely that only few researchers are able to produce highly innovative research and simultaneous maximize the number of their publications. Editorial boards may be more interested in innovative research and less interested in the number of publications.

Third, although both the arguments cited above assume that scholars who are invited to be editorial members do not maximize their number of publications, it is also possible that scholars with a large publication record are nevertheless asked to participate in editorial boards, but are less willing to engage in this task. Being a member of an editorial board entails constraints on time and effort. There is less time for publishing, and some scholars may prefer to publish instead of serving on editorial boards.

Thus, it seems plausible to assume that the relation between a scholar's position in the quantitative and qualitative rankings has a curvilinear shape. While a minimum of publications may be important to guarantee the recognition of a scholar as a possible editorial board member, too many publications may reflect a lack of investment in multiple other tasks, which are also essentially important for editorial board members. This leads to the hypothesis that we test empirically:

Hypothesis 1: As measured in our qualitative ranking, the publication record of individual scholars, as measured in quantitative rankings, shows an inverted U-shaped relation to the probability of being selected as an editorial board member.

\section{Comparison between Quantitative and Qualitative Rankings}

\subsection{SAMPLE}

To analyze the systematic nonlinear relation between quantitative and qualitative rankings, we use a sample of journals that are considered to enjoy an excellent international reputation within the field of management and organization. This sample is representative for researchers who publish papers on dominant theories within this research community. We expect similar effects for other sciences, and for lower-ranked journals. However, we note that our sample does not provide a comprehensive overview of all research communities 
within the organization management community. In particular, we exclude heterodox research communities that embrace contested knowledge (Lee (2008)).

To determine the boundaries of our sample of journals, we proceed in three steps. First, to include only one and not several citation and publication habits we draw on personal experience which journals are read and considered as possible publication outlets by scholars of the organization management community. We exclude ancillary journals that are strongly related to other fields, e.g., to psychology, innovation management, accounting, finance, marketing etc.

Second, to bypass the obscure weighting of articles by impact factors, we validate the impact homogeneity of our sample by using different journal rankings. Table 1 presents the various ranking positions of the journals we use. Columns II and III indicate that the journals maintain top-level positions when we consider only management and business journals of the ISI web of knowledge ${ }^{18}$. Column I shows that all journals have high journal impact factors reaching from 1.5 up to five. Columns IV, V, and VI show that all publication outlets are classified as $\mathrm{A}+, \mathrm{A}$, or $\mathrm{B}$ journals within the several rankings. Column VII contains our measurement of journal impact. It measures how often an article is cited, correcting for the number of references and thus for sub-community size. More references increase the likelihood of citations, which should be taken into account. According to this measure, particularly those journals that are lower ranked in the former standard proceedings have a higher impact within their subdiscipline ${ }^{19}$.

We collect data on all articles and reviews published in the journals selected within the time period 1997-2007. We exclude book reviews, editorial material and proceedings. We also exclude publications for the years 2008/2009 for two reasons. First, because we measure editorial board membership in the year 2009. The time lag ensures that our rankings exclude authors who started to publish their research in 2008/2009, and who thus had no chance of being considered a possible board candidate. Second, because we use the average number of yearly citations and the journal impact factor as control measures. On average, articles get the most citations within two years after they are published (Garfield (1979)). This information helps us to standardize citation rates. To identify several articles by one scholar and his or her editorial board membership, we check the data by using the institutions and countries of scholars with misleading names or initials of first names.

18 The missing ranking positions are shared by marketing and finance journals, i.e., by different research communities.

19 We further cross-validated the community-aspect by analyzing journal relatedness. First, we evaluated the percentage of citations between the journals (information available in ISI web of knowledge). The results substantiated that the included journals often refer to each other indicating one community. Second, we examined how often authors have articles in two or more of the included journals. The findings validated that many scholars indeed publish in several journals of our sample. Third, we examined how often scholars are editor board members in two or more of the included journals. The findings validated that the included journals are related to each other by cross-editorship. 
Table 1: Top-journals of the management and organization research community

\begin{tabular}{|c|c|c|c|c|c|c|c|}
\hline & 1 & II & III & IV & V & VI & VII \\
\hline Journal & $\begin{array}{l}\text { Rank/ } \\
2007 \\
\text { JCR }^{1}\end{array}$ & $\begin{array}{c}2007 \\
\text { JCR }{ }^{1} \text { Rank of } \\
81 \text { Manage- } \\
\text { mentJ. }\end{array}$ & $\begin{array}{c}2007 \\
\text { JCR } 1 \text { Rank } \\
\text { of } 129 \\
\text { BusinessJ. }\end{array}$ & $\begin{array}{l}2009 \\
H B^{2} B W L\end{array}$ & $\begin{array}{c}2008 \\
\text { Jourqual }^{3} \\
\text { wiss. } \\
\text { Qualität }\end{array}$ & $\begin{array}{c}2008 \\
\text { Jourqual } \\
\text { Rating }^{3}\end{array}$ & $\begin{array}{c}\text { Rank/ } \\
\text { 1997-2007 } \\
\text { Citations } \\
\text { per } \\
\text { Reference }\end{array}$ \\
\hline $\begin{array}{l}\text { Academy of } \\
\text { Management Journal }\end{array}$ & (1) 5.02 & (2) & (2) & 1 & 9.08 & $A+$ & (11) 1.27 \\
\hline $\begin{array}{l}\text { Academy of } \\
\text { Management Review }\end{array}$ & (2) 4.37 & (3) & (3) & 1 & 9.07 & $A+$ & (9) 1.49 \\
\hline Organization Science & (3) 3.13 & (4) & (6) & 0.7 & 8.90 & A & (7) 2.38 \\
\hline $\begin{array}{l}\text { Administrative } \\
\text { Science Quarterly }\end{array}$ & (4) 2.91 & (5) & (7) & 1 & 9.48 & $A+$ & (10) 1.43 \\
\hline $\begin{array}{l}\text { Strategic } \\
\text { Management Journal }\end{array}$ & (5) 2.83 & (6) & (8) & 0.7 & 8.41 & A & (8) 1.77 \\
\hline $\begin{array}{l}\text { Journal of Intern. } \\
\text { Business Studies }\end{array}$ & (6) 2.28 & (10) & (12) & 0.7 & 8.81 & A & (5) 3.33 \\
\hline Organization Studies & (7) 2.04 & (12) & (15) & 0.7 & 7.99 & B & (3) 5.30 \\
\hline $\begin{array}{l}\text { Journal of } \\
\text { Management }\end{array}$ & (8) 2.00 & (13) & (16) & 0.7 & 7.85 & B & (6) 3.27 \\
\hline $\begin{array}{c}\text { Journal of } \\
\text { Organizational } \\
\text { Behavior }\end{array}$ & (9) 1.98 & (14) & (17) & 0.7 & 7.40 & B & (4) 3.41 \\
\hline $\begin{array}{l}\text { Journal of } \\
\text { Management Studies }\end{array}$ & (10) 1.93 & (16) & (19) & 0.7 & 7.55 & B & (2) 6.19 \\
\hline $\begin{array}{l}\text { British Journal of } \\
\text { Management }\end{array}$ & (11) 1.53 & (27) & (36) & 0.5 & 7.28 & B & (1) 8.96 \\
\hline \multicolumn{8}{|c|}{$\begin{array}{l}\text { Journal Citation Report (JCR) of the ISI Web of Knowledge (The Thomson Corporation (2008)). JCR indicates } \\
\text { how often an article gets cited within the first two years after publishing. }\end{array}$} \\
\hline \multicolumn{8}{|c|}{$\begin{array}{l}\text { Handelsblatt (HB) Ranking BWL (Handelsblatt (2009)). Journals scores reach from one to zero. Higher value } \\
\text { indicates higher journal impact. Journal scores are obtained from a combination of journal citation reports } \\
\text { and reputation rankings. }\end{array}$} \\
\hline \multicolumn{8}{|c|}{$\begin{array}{l}\text { Official journal ranking of the VHB (Hennig-Thurau, Welsh, and Schrader (2004)). Higher values indicate } \\
\text { higher journal impact. We obtain journal scores from survey data and intend to capture quality aspects. }\end{array}$} \\
\hline $\begin{array}{l}4 \text { Self-constructed me } \\
T=1997-2007, N=5\end{array}$ & asuremen & $\begin{array}{l}\text { at: Journal Imp } \\
\text { ors with 5,509 }\end{array}$ & $\begin{array}{l}\text { oact }=\sum \text { refer } \\
\text { articles. }\end{array}$ & ences per a & rticle/ $/$ citati & ons per arti & cle. Sample: \\
\hline
\end{tabular}

\subsection{Dependent Variable}

Editorial board membership. In May 2009 we consulted the homepage of each journal in our sample and collected the names of scholars who were serving as editors, coeditors, or board members at that time. There are two possible definitions of editorial board membership. The broadest possible definition includes all positions, i.e., editor, co-editor, and board member. In our initial sample 1,316 persons held at least one editor, co-editor, or board position; $16.4 \%$ individuals had more than one position. We 
construct a variable Editor Board Membership for 2009, identifying the number of editor, co-editor or board member positions of a person. In the second definition, board definition includes only board member positions. In our initial sample 1,181 persons held at least one board position; $15.3 \%$ had more than one position. We construct a variable Board Membership, which indicates the number of board member positions of a person in 2009 .

We find that 465 scholars, all board members, had not published an article in any of the journals selected during the last ten years. This finding is a first indication of the accuracy of our hypothesis, suggesting that the publication record of scholars does not inevitably reflect his or her ability to perform well as an editorial board member. However, the finding could reflect the need for appropriate representation, e.g., for the representation of different countries. We exclude these scholars without publications from our statistical analysis because it is possible that the empirical findings are driven by lazy scholars sitting in editorial boards ${ }^{20}$. For the regression analysis our measurements of Editor Board Membership examine 851 active editors, co-editors, or board members, and for Board Membership 716 active board members.

\subsection{INDEPENDENT VARIABLE}

Publication record. For each author we count all articles published in the selected journals. We adjust for tenure effects, since experienced scholars have a higher probability of being a board member. For each scholar we calculate the yearly number of articles published beginning with the year of his or her first publication. For example, if a scholar published his or her first article in the year 2000, we average the number of articles over eight years. The year of entry into the research community is a better adjustment for tenure effects compared with age. Age does not account for the effective time a scholar is part of the community. In particular, U.S. scholars often start their research careers after they have careers in the industry.

\subsection{Control Variables}

We also include several control variables that may affect editorial board membership, and which are related to the publication record of a scholar but do not necessarily reflect quality aspects.

Co-authorship. We consider the average number of co-authors per article. For each scholar we use the sum of co-authors over all articles and divide it by the number of articles. Scholars with a higher number of co-authors may increase the number of published articles due to economies of scale. Further, they may have a higher direct influence within their research community and thus a higher likelihood of becoming a board member.

20 However, the empirical findings are comparable if we include editors without publications. 
Citations. We measure the average number of citations per article for every author. The index is a proxy of scholars' visibility, for example, due to conducting high-quality research, publishing dominant theories, being the target of herding behaviour, or engaging in citation networks (Moed et al. (1985)). Authors who have high visibility may increase their publication record and their likelihood of becoming a board member. We adjust the number of citations by the age of each publication.

$$
\text { Citations }=\frac{\sum \frac{\sum \text { Citations per Article }}{\text { Age of publication }}}{\sum \text { Articles }}
$$

Journal Impact. We also use The Thomson Corporation (2008) index to control for the average journal impact factor per article. This index measures the likelihood of board membership due to reputation effects. Authors who publish in highly visible journals may gain higher visibility themselves.

Entry Year. Even though we adjust the publication record for tenure effects, we also control for entry year, i.e., the year of the first publication. Established scholars have a higher probability that an academic will become an editorial board member. Authors can demonstrate a continuous publication history and could have accumulated a higher stock of expert knowledge. They may also have higher social capital. Because of their expert knowledge, experience, and social capital, such scholars may have a higher yearly publication record.

Pages. We measure the average number of pages per article. Longer articles may be an indication for more essential research (Hofmeister and Ursprung (2008)) and thus increase the probability of publishing or becoming an editorial board member. However, the length of an article may not necessarily reflect quality aspects. It could also reflect different research streams (e.g., theoretical research). Both issues may affect an academic's publication record and editorial board membership.

\subsection{Independent Variable for Robustness Test}

Corrected Research Output. We test the robustness of our results by applying an adjusted indicator for research evaluation as suggested by Hofmeister and Ursprung (2008). Instead of counting the number of A+ articles, this output measurement captures quality and effort aspects. The index multiplies the number of pages with the journal impact factor and corrects for the number of co-authors. Hofmeister and Ursprung (2008) suggest applying this index within the Handelsblatt-Ranking ${ }^{21 \& 22}$.

21 Currently, the following formula is applied:

The formula corrects for the number of co-authors, but not in a linear way. For example, in a journal with the impact " 1 " an article without co-authors obtains the value " 1 ", with one co-author the value ".67" and with two co-authors the value ".5".

22 For descriptive statistics and bivariate correlations please contact the authors. 


$$
\text { Corrected Research Output }=\frac{\sum \frac{\sum \text { Pages per Article * Journal Impact per Article }}{\text { Co-authors per Article }}}{\text { publication tenure }}
$$

\subsection{ANALYSIS}

We use Poisson regression analysis to predict the dependent count variables Editor Board Membership and Board Membership and include the linear and quadratic term of publication record. The distributions of the independent variables publication record, co-authorship, citations, and pages are extremely skewed and may corrupt the regression results due to outliers. We transform these variables by taking the logarithm.

$$
\begin{aligned}
\log & (\text { E(Editor Board Membership }) \mid x i)=a+b 1(\log \text { Publication record }) \\
& +b 2\left(\log \text { Publication record }{ }^{2}\right)+b 3(\log \text { Co-authorship }) \\
& +b 4(\log \text { Citations })+b 5(\log \text { Pages })+b 6(\text { Journal Impact }) \\
& +b 7(\text { Entry Year })
\end{aligned}
$$

We apply three robustness checks. First, we run separate regression models for each entry year. Second, for one of the most important journals, we run a regression model that includes former editorial board members. Third, we test if our results hold for the corrected measure of research output.

\section{Empirical Results}

\subsection{Descriptive Findings}

Table 2 presents the results of a ranking of scholars according to the number of editorial boards on which they serve. The table shows every scholar who holds three or more Editor Board Membership positions. The table compares their positions with the position of those scholars in two publication rankings. To obtain publication positions, we rank all scholars of our sample according to their yearly publication record and corrected research output in our sample ${ }^{23}$. The results show that among the 48 scholars holding three or more editorial board positions, only three would be ranked among the 100 most successful scholars in a ranking according to publication record. The table further shows that if they were ranked according to corrected research output, then only three of these authors would be ranked among the 100 most successful scholars. Figure 1 illustrates how an editorial board membership ranking is related to a ranking according to the publication record of

23 Of course we could argue that all publications of these scholars should be included, not just their publications in the 11 journals. However, all rankings are restricted to this list of journals and only articles published in these journals were counted. In contrast to many rankings, we did not select our journal list randomly, but by means of community aspects. 
Table 2: Editorial boards according to individual scholars

\begin{tabular}{|c|c|c|c|c|}
\hline Scholar Name & $\begin{array}{l}\text { Number of Editor Board } \\
\text { Membership Positions } \\
\text { (editor, co-editor or } \\
\text { board member) }\end{array}$ & $\begin{array}{l}\text { Number of Editor } \\
\text { Positions } \\
\text { (editor, co-editor) }\end{array}$ & $\begin{array}{c}\text { Publication Record } \\
\text { (Ranking Position } \\
\text { according to Publication } \\
\text { Record) }\end{array}$ & $\begin{array}{c}\text { Corrected Research } \\
\text { Output (Ranking } \\
\text { Position according to } \\
\text { Corrected Research } \\
\text { Output) }\end{array}$ \\
\hline Cannella, AA & 6 & 0 & $0.97(82)$ & 38.35 (131) \\
\hline Reuer, JJ & 5 & 2 & $0.93(93)$ & $31.07(213)$ \\
\hline Floyd, SW & 5 & 2 & $0.73(213)$ & 16.83 (792) \\
\hline Inkpen, A & 5 & 0 & $0.69(488)$ & $24.89(381)$ \\
\hline Hodgkinson, GP & 5 & 0 & $0.69(488)$ & $6.2(2463)$ \\
\hline Lepak, D & 5 & 1 & $0.44(1188)$ & $10.72(1466)$ \\
\hline Hitt, MA & 4 & 0 & $1.29(18)$ & $49.07(73)$ \\
\hline Lounsbury, M & 4 & 2 & $0.76(183)$ & $49.65(72)$ \\
\hline Cornelissen, JP & 4 & 2 & $0.69(488)$ & 34.67 (160) \\
\hline Kostova, $T$ & 4 & 0 & $0.64(798)$ & $29.24(249)$ \\
\hline Henisz, WJ & 4 & 2 & $0.63(809)$ & 27.61 (302) \\
\hline Ashkanasy, NM & 4 & 2 & $0.63(809)$ & $12.79(1205)$ \\
\hline Foss, NJ & 4 & 0 & $0.51(1010)$ & $17.19(766)$ \\
\hline Bartunek, JM & 4 & 0 & 0.49 (1091) & $16.48(817)$ \\
\hline Jarzabkowski, P & 4 & 0 & $0.34(2021)$ & 15 (949) \\
\hline Maitlis, S & 3 & 0 & $0.88(124)$ & $73.14(20)$ \\
\hline George, JM & 3 & 0 & $0.88(124)$ & $26.68(330)$ \\
\hline Dobrev, SD & 3 & 0 & $0.76(183)$ & $41.76(105)$ \\
\hline Birkinshaw, J & 3 & 0 & $0.75(189)$ & $22.93(444)$ \\
\hline Greenwood, R & 3 & 0 & $0.74(198)$ & $30.73(215)$ \\
\hline Hoskisson, RE & 3 & 2 & $0.74(198)$ & 24.1 (394) \\
\hline Filatotchev, I & 3 & 0 & $0.74(198)$ & $16.01(868)$ \\
\hline McNamara, GM & 3 & 0 & $0.7(219)$ & 20.7 (539) \\
\hline Shen, W & 3 & 0 & $0.69(488)$ & $28.97(256)$ \\
\hline Certo, ST & 3 & 0 & $0.69(488)$ & $19.01(645)$ \\
\hline Takeuchi, R & 3 & 0 & $0.69(488)$ & $16.05(852)$ \\
\hline Chang, SJ & 3 & 2 & 0.64 (798) & $28.99(255)$ \\
\hline Roth, K & 3 & 1 & $0.64(798)$ & $26.01(356)$ \\
\hline Brass, DJ & 3 & 0 & $0.64(798)$ & $19.85(582)$ \\
\hline Bansal, P & 3 & 0 & $0.63(809)$ & $29.49(247)$ \\
\hline Makino, S & 3 & 0 & $0.61(832)$ & $16.41(820)$ \\
\hline Delios, A & 3 & 2 & $0.61(832)$ & $2.36(4180)$ \\
\hline Balogun, J & 3 & 0 & $0.59(854)$ & $23.53(415)$ \\
\hline Ethiraj, SK & 3 & 0 & $0.56(893)$ & $30.4(220)$ \\
\hline George, G & 3 & 0 & $0.56(893)$ & $21.72(494)$ \\
\hline Swaminathan, A & 3 & 2 & $0.53(957)$ & $24.67(385)$ \\
\hline Tallman, SB & 3 & 2 & $0.53(957)$ & $11.5(1363)$ \\
\hline Baker, T & 3 & 0 & $0.51(1010)$ & $21(524)$ \\
\hline Anand, J & 3 & 0 & $0.49(1091)$ & 13.75 (1089) \\
\hline Jensen, $M$ & 3 & 0 & 0.47 (1119) & $40.92(111)$ \\
\hline Sorge, A & 3 & 1 & 0.47 (1119) & $14.91(956)$ \\
\hline Durand, R & 3 & 0 & $0.45(1162)$ & 17.78 (729) \\
\hline Delbridge, R & 3 & 0 & $0.44(1188)$ & $6.01(2535)$ \\
\hline Suddaby, R & 3 & 0 & $0.41(1542)$ & $22.68(455)$ \\
\hline Chattopadhyay, P & 3 & 0 & $0.37(1870)$ & $14.5(1012)$ \\
\hline Sparrowe, RT & 3 & 0 & $0.37(1870)$ & $12.71(1207)$ \\
\hline Seidl, D & 3 & 0 & $0.34(2021)$ & $12.62(1216)$ \\
\hline Robson, M & 3 & 1 & $0(5635)$ & $0(5387)$ \\
\hline
\end{tabular}

The table includes all persons with three or more board memberships (according to the broad definition). 
an author. The results show that many scholars listed in a publication ranking in the foremost ranks would not even be listed in a quality ranking, while many academics listed in a board membership ranking in the foremost ranks would be listed in a quantity ranking in the lowest ranks. The results confirm that a ranking of individual scholars depends heavily on the type of ranking used and thus confirm the results of our first study on this topic (Frey and Rost (2010)).

\section{Figure 1: Ranking comparison of individual scholars according to publication} record and editorial board membership

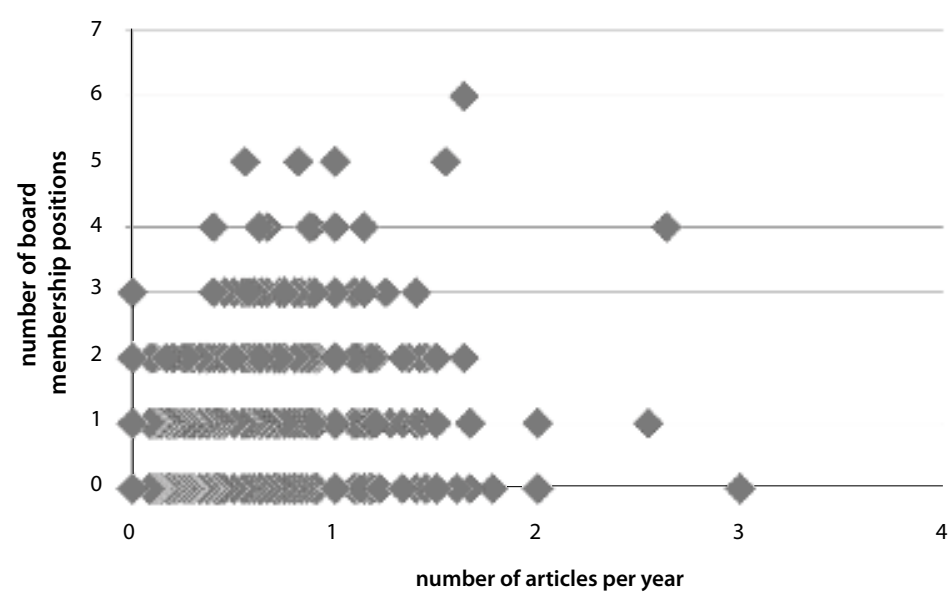

\subsection{Statistical Findings}

Table 3 shows the results of the Poisson regression analysis for Editor Board Membership and Board Membership.

Linear model. In the linear model, an academic's publication record shows a strong positive effect on the number of board membership positions (see Columns I and III). The explanatory power of the model significantly improves if we include the linear term of publication record. (Model Improvement for editor board membership: 20.85***, Model Improvement for board membership: 12.93***) The results show that in general, scholars with more publications have a higher probability of being selected as a board member.

Quadratic model. Columns II and IV report the results when we also include the quadratic terms of publication record. Compared with the linear model, the explanatory power significantly improves if we include the quadratic term (Model Improvement for editor board membership: 149.08***, Model Improvement for board membership: $\left.130.30^{* * *}\right)$. When we compare the LR-Chi ${ }^{2}$ statistisc, which indicate the improvement of 
Table 3: Determinants of board and editor board membership

\begin{tabular}{|c|c|c|c|c|c|c|c|c|c|c|c|c|}
\hline \multirow[t]{2}{*}{ Dependent Variable: } & \multicolumn{6}{|c|}{ Board Membership } & \multicolumn{6}{|c|}{ Editor Board Membership } \\
\hline & Coef. & SD & Sig. & Coef. & SD & Sig. & Coef. & SD & Sig. & Coef. & SD & Sig. \\
\hline & $\mathbf{I}$ & & & II & & & III & & & IV & & \\
\hline (Constant) & 69.89 & 30.96 & * & 163.93 & 33.25 & $* * *$ & 46.60 & 33.15 & & 142.68 & 35.57 & $* * *$ \\
\hline $\begin{array}{l}\text { Publication record } \\
\text { (Inskew0) }\end{array}$ & 1.08 & 0.23 & $* * *$ & 7.36 & .65 & $* * *$ & 0.92 & 0.25 & $* * *$ & 7.40 & 0.71 & $* * *$ \\
\hline $\begin{array}{l}\text { Publication record } \\
(\text { Inskew0) }\end{array}$ & & & & -5.68 & .57 & $* * *$ & & & & -5.96 & 0.64 & $* * *$ \\
\hline Co-authorship (Inskew0) & 1.53 & 0.12 & $* * *$ & 1.26 & .13 & $* * *$ & 1.58 & 0.13 & $* * *$ & 1.31 & 0.14 & $* * *$ \\
\hline Citations (Inskew0) & 0.14 & 0.06 & $* *$ & 0.20 & .06 & $* * *$ & 0.17 & 0.06 & $* *$ & 0.23 & 0.06 & $* * *$ \\
\hline Pages (Inskew0) & 0.38 & 0.11 & $* * *$ & 0.37 & .11 & $* * *$ & 0.36 & 0.11 & $* * *$ & 0.33 & 0.12 & $* *$ \\
\hline Journal Impact & 0.18 & 0.04 & $* * *$ & 0.15 & .04 & $* * *$ & 0.21 & 0.04 & $* * *$ & 0.17 & 0.04 & $* * *$ \\
\hline Entry Year & -0.04 & 0.02 & * & -0.08 & .02 & $* * *$ & -0.03 & 0.02 & & -0.07 & 0.02 & $* * *$ \\
\hline Pseudo $R^{2}$ & & .192 & & & .216 & & & .174 & & & .196 & \\
\hline Log likelihood & & -2513.74 & & & -2439.20 & & & -2360.36 & & & -2295.21 & \\
\hline LR-Chi ${ }^{2}$ & & 1397.09 & $* * *$ & & 1346.17 & $* * *$ & & 991.72 & $* * *$ & & 1122.02 & $* * *$ \\
\hline $\begin{array}{l}\text { Model Improvement } \\
\text { LR Chi }{ }^{2} \text { by including } \\
\text { Publication record } \\
\text { (Inskew0) }\end{array}$ & & 20.85 & $* * *$ & & & & & 12.93 & $* * *$ & & & \\
\hline $\begin{array}{l}\text { Model Improvement } \\
\text { LR Chi }{ }^{2} \text { by including } \\
\text { Publication record } \\
(\text { Inskew } 0)^{2}\end{array}$ & & & & & 149.08 & $* * *$ & & & & & 130.30 & $* * *$ \\
\hline \multirow[t]{2}{*}{$N$} & & 5,794 & & & 5,794 & & & 5,794 & & & 5,794 & \\
\hline & V & & & VI & & & VII & & & VIII & & \\
\hline (Constant) & 362.20 & 19.13 & $* * *$ & 359.64 & 19.16 & $* * *$ & 376.59 & 18.08 & $* * *$ & 373.73 & 18.10 & $* * *$ \\
\hline $\begin{array}{l}\text { Corrected Research } \\
\text { Output (Inskew0) }\end{array}$ & .91 & .03 & $* * *$ & 1.17 & .13 & $* * *$ & .93 & .03 & $* * *$ & 1.25 & .13 & $* * *$ \\
\hline $\begin{array}{l}\text { Corrected Research } \\
\text { Output (Inskew0) }\end{array}$ & & & & -.06 & .03 & * & & & & -.07 & .03 & $* *$ \\
\hline Citations (Inskew0) & -.01 & .01 & & -.01 & .01 & & -.01 & .01 & & -.01 & .01 & \\
\hline Entry Year & -.18 & .01 & $* * *$ & -.18 & .01 & $* * *$ & -.19 & .01 & $* * *$ & -.19 & .01 & $* * *$ \\
\hline Pseudo $R^{2}$ & & .158 & & & .158 & & & .173 & & & .174 & \\
\hline Log likelihood & & -2406.28 & & & -2403.91 & & & -2575.53 & & & -2571.83 & \\
\hline $\mathrm{LR}^{-C h \mathrm{i}^{2}}$ & & 899.88 & $* * *$ & & 904.61 & $* * *$ & & 1073.52 & $* * *$ & & 1080.92 & $* * *$ \\
\hline $\begin{array}{l}\text { Model Improvement } \\
\text { LR Chi }{ }^{2} \text { by including } \\
\text { Publication record } \\
\text { (Inskew0) }\end{array}$ & & 746.49 & $* * *$ & & & & & 876.68 & $* * *$ & & & \\
\hline $\begin{array}{l}\text { Model Improvement } \\
\text { LR Chi }{ }^{2} \\
\text { by including Publication } \\
\text { record (Inskew0) }\end{array}$ & & & & & 4.73 & * & & & & & 7.40 & $* *$ \\
\hline$N$ & & 5,794 & & & 5,794 & & & 5,794 & & & 5,794 & \\
\hline
\end{tabular}

Poisson Regression, $+p<0.10,{ }^{*} p<0.05,{ }^{* *} p<0.01,{ }^{* * *} p<0.001$.

Inskew0 indicates the zero-skewness logarithm of a variables, i.e., the variable is added with the constant " 1 " so that the logarithm can be also taken from values of zero. 
the explanatory power of a statistical model, between the linear and quadratic models, we see that a model that includes the quadratic model is significantly better able to explain the appointment of scholars in editorial boards. Thus, even if the overall effect of the publication record on board membership is positive, the link between the measure of quantitative rankings and the measure of qualitative rankings is not strictly linear.

\section{Figure 2: Predicted relation between publication record and board membership}

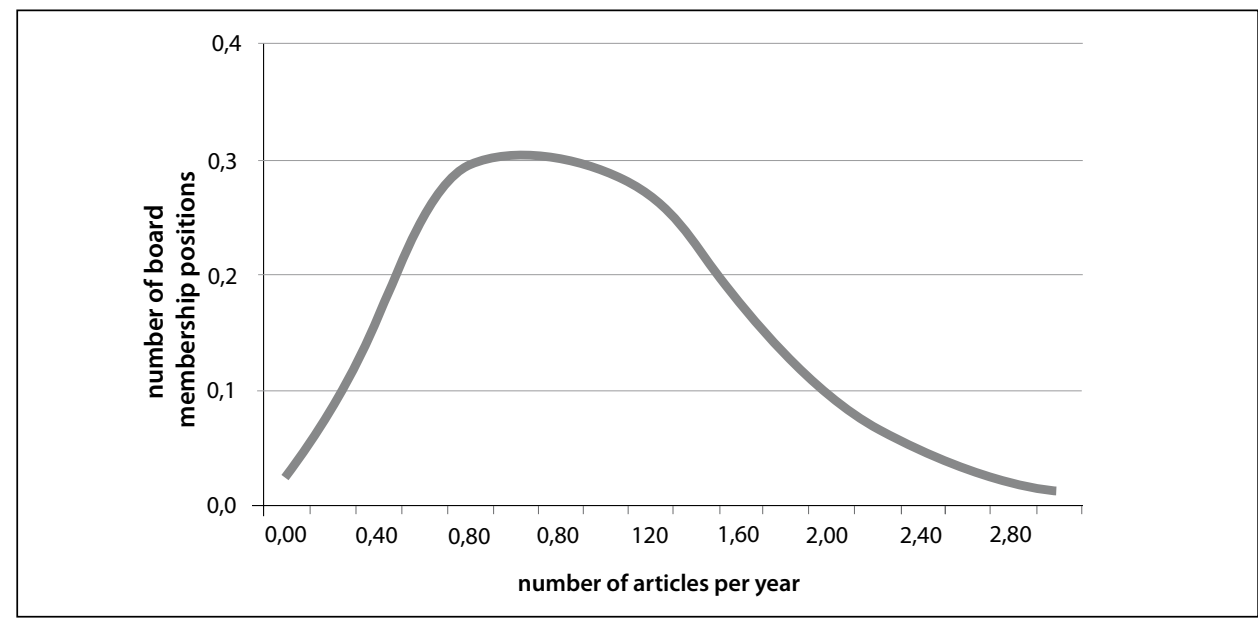

Figure 2 shows the predicted curve shape for the example of board membership (results of Table 3, Column II). The results support our hypothesis by showing that the publication record of an academic shows an inverse, U-shaped relation to his or her number of editorial board membership positions. According to the results, authors with a yearly publication record of around 0.8 articles have the highest chance of being elected to a board membership. But both a lower and a higher publication record decreases this probability. This finding shows that journals are indeed interested in appointing board members who show a continuous publication history, but they are not interested in having board members who have a very large number of publications.

\subsection{Robustness Checks}

We perform three robustness checks to validate our results.

First, we analyze the data to see if the curvilinear relation is driven by tenure effects. Even if we control for the year of first publication, it is possible that even experienced scholars will show a medium or low publication record. Therefore, we divide the sample into subgroups by using the variable entry year and run separate regressions for groups of authors who start to publish within the same year. The results show that the curvilinear 
effect of the publication record is robust and significant ${ }^{24}$. The effects get weaker for scholars with very short community tenure.

Second, we analyze the data to see if the inclusion of former board members would change the results. Since many journals rotate their editorial boards, it may be the case that researchers are no longer members of the board but are still well respected. Including these scholars could change our results. We select the Academy of Management Journal (AMJ) because it had recently changed its editorial board. We predict the membership in the current and/or former AMJ board by including the data for all authors who had published at least one AMJ article between 1997 and 2007. Including these individuals does not change our general findings of a curvilinear effect of publication record on board membership ${ }^{25}$. We also validate the findings on the AMJ board by excluding all academics who have already served as a board member but who were not serving on the board in 2009. The findings also show a significant curvilinear effect.

Third, proponents of quantitative rankings often argue that if they are correctly administered, rankings measure every aspect of research quality. For example, Hofmeister and Ursprung (2008) suggest that the quality and effort aspects of research are better captured if output indicators multiply the number of pages per article by the journal impact factor of an article and also correct for the number of co-authors. We count the index for every scholar in our sample. Table 3 shows the results.

In the linear model the results again show that academics with a higher research output have more board member positions (Columns V and VII). Columns VI and VIII report the results when we also include the quadratic terms of research output. The negative and significant quadratic terms again support that the corrected research output of a scholar also shows an inverse, U-shaped relation to his or her number of board membership positions. However, compared to the linear model, the additional explanatory power of the quadratic model is lower, as we can see in Table 3. It indicates that the corrected research output of a scholar may be a better measurement of research quality than simple publication counts. But even the corrected measure of quantitative rankings and the measure of qualitative rankings is not strictly linear. The results thus substantiate that quantitative and qualitative rankings do not show the same results with respect to the position of scholar within both rankings.

We also perform robustness checks by calculating research output with a formula that, instead of using the journal impact factor, values an A+ level publication at nine, an A-level publication at three, and a B-level publication at one. (We measure journal quality according to the Jourqual 2008.) These results are comparable to the results in Table 3.

We note that we are not able to overcome possible endogeneity problems. It seems plausible that the election of an academic to editorial boards may increase his or her publication output. However, this bias should be small, because the U-shaped relation be-

24 The results are available on request from the authors.

25 For the results please contact the authors. 
tween publication output and editorial board membership suggests that editorial board members do not have a maximum of publications.

\section{Discussion and Conclusion}

We argue that quantitative rankings, e.g., publication or citation measures, capture only some aspects of scientific research quality (see also Frey and Rost (2010)). For that reason, we have developed an alternative ranking system that is based on membership on academic editorial boards of professional journals. This qualitative ranking considers the reputation and recognition of scholars among their peers, and recognizes their contributions to the research community in terms of reading and reviewing the work of others.

In this article we compared the results of quantitative and qualitative rankings of individual scholars in a more systematic way. The empirical results indicate that the position of a scholar in qualitative rankings, i.e., using the selection in editorial boards as a quality indicator, is not strictly related linearly but instead shows an inverted U-shape to his/her position in quantitative rankings, i.e., his/her number of (A+) publications. Especially for scholars who score high in publication rankings, our study suggests that rankings based on the quantity of publications are incompatible with rankings based on membership on editorial boards. This finding suggests that the two indexes do not measure the same phenomenon. Science needs both types of scholars; those who are productive in terms of publishing and those who are productive in terms of running journals. For that reason, research evaluations should consider multiple criteria rather than just publication or citation counts.

This conclusion is in line with prior research. Henrekson and Waldenstrom (2007) rank every full professor in economics in Sweden using seven established measures of research performance. Their analysis shows that the ranking can vary greatly across measures and that depending on the measure used, the distribution of total research output is valued very differently. This finding is also validated by other authors (Coupé (2003); Donovan and Butler (2007); Lo, Wong, and Mixon (2008)) who suggest that research quality can only be captured through multiple indicators. This result is in line with bibliometric research that warns against using publications and citations as the only measure for capturing the research effort of individuals, especially individuals in the social sciences (van Raan (2003)).

For the career decisions of individual scholars, bibliometric rankings should be used with utmost care. "Crude rankings ... cannot be helpful to the policy maker" (Johnes (1988)). Funding agencies and other decision makers who must evaluate the research efforts of individual researchers or of the whole university sector should go beyond applying standard quantitative measures of research performance to the social sciences (Katz (1999); Luwel et al. (1999); Council for the Humanities Arts and Social Sciences (2005)). Research quality is diverse, uncertain, and multidimensional. It is highly questionable that there exists just one, true indicator of research quality that captures the efforts of scientists within all research communities to the same extent. In some communities, for example, 
only empirical research constitutes good research, while in other communities it is more important to pose a novel research question or to contribute an original theory. For this reason, indicators that capture research quality are not only multidimensional, but also highly dependent on the specific research community.

But what are the alternatives for research evaluation? One way to solve the multipletasking problem would be to measure all the aspects that are important for an academic career: teaching, supporting younger scholars, connecting to the public, and participating in academic administration or editorial board membership (Frey (2010)). However, attempting to measure all important aspects would lead to an enormous amount of evaluation, and scholars would invariably find ways to 'beat the system'.

A different option would be to return to approved methods, i.e., to an overall evaluation of (young) scholars based on the intuition and knowledge of seasoned scholars (Frey (2010)). There are various ways to select such persons. An attractive option would be to elect them by a vote among the members of the respective professional organization. Doing so would ensure that the peers making up the so-called "Republic of Science" would remain in control. The academics selected by such a procedure would be under the scrutiny of the profession as a whole and would lose their reputation among their peers if they pushed unfounded personal interests. The scholars who were chosen would have an incentive to decide as objectively as possible while maintaining an unbiased perspective. This option offers the members of professional organizations more competence and control compared to the system prevailing today, and helps them to fight the unilateral tendency of young scholars to put their whole effort into publishing A-level articles while neglecting other tasks. Nevertheless, such a procedure is viewed as "unscientific", as it is not based on the allegedly objective calculation of publications in A-level journals. But such a view is too simple. According to recent psychological research, "gut feelings" are often superior to indepth analyses (Gladwell (2005); Gigerenzer (2007)). Indeed, many established scholars proceed intuitively when they exchange their views about younger scholars. What matters to them is that they feel good about a young scholar, and not whether someone has published an article in a particular A-level journal. Using the gut feelings of seasoned scholars has, of course, disadvantages. There is certainly the danger of promoting an "old boys' network", thus giving young scholars an incentive to pander to the seasoned scholars. Personality and friendship may matter more than research excellence because gut feelings are to some extent influenced by such perceptions. On the other hand, these alleged disadvantages should not be overrated. It is important to remember that the present system, which focuses on A-level journal publications, is also influenced by personal relationships and preferences, as well as by selfish interests. It has, for instance, become common practice to abundantly and positively cite possible referees to raise the chance of acceptance. Even more importantly, scholars in dire need of having their articles published feel that they must follow the referees' "advice" even if those directives differ from their own insights and views. This behavior has been called "academic prostitution" (Frey (2003)).

A third possibility is to restrict publication rankings to the early years of a scientific career (Osterloh and Frey $(2008 ; 2010)$ ). Scientists must first learn the tools of the trade and must show that they are able to use them well. Thereafter, scholars should be able to proceed 
as they see fit for themselves. This restriction allows them to then exhibit their inherent motivation in scientific research for at least the remaining part of their careers. An obvious disadvantage of the restriction of publication rankings to the early years of a scientific career is that scholars in later stages of their careers are not subjected to any external monitoring and may no longer engage in research. This may well be the case, but an academic system could be designed to enable the best rather than to prevent the worst.

Yet another possibility would be to more openly shape several levels of scientific careers (Frey (2010)). In particular, there should be careers at universities and research institutes for which it is sufficient to have published in one or a few of the hundreds of general and specialized journals, or to have been published in the books and internet publications, or to have participated in current public debates. Such a policy would produce a broader portfolio in the management profession with respect to type of contribution, content, techniques, and universities. Through the present focus on A-level publications, diversity - a crucial requirement to guarantee originality - is indeed threatened as (Osterloh and Frey (2008)).

Each of these (and possibly other) options has both its advantages and disadvantages, all of which must be carefully considered. This article does not promulgate any of the options discussed. However, we do want to call attention to the major shortcomings of quantitative rankings: Publication or citation rankings ignore important scholarly contributions, e.g., the investment in multiple and/or difficult tasks, which are important for research. Thus, in the long run, quantitative research rankings may crowd out such contributions, worsening, instead of improving, research quality.

\section{APPENDIX}

Table A1: Descriptive statistics and bivariate correlations

\begin{tabular}{|c|c|c|c|c|c|c|c|c|c|c|c|c|}
\hline Nr. & Variable & Mean & SD & 1 & 2 & 3 & 4 & 5 & 6 & 7 & 8 & 9 \\
\hline 1 & Editor Board Membership & .26 & .56 & 1.00 & & & & & & & & \\
\hline 2 & Board Membership & .22 & .51 & .94 & 1.00 & & & & & & & \\
\hline 3 & Publication record (Inskew0) & .28 & .21 & .27 & .24 & 1.00 & & & & & & \\
\hline 4 & Co-authorship (Inskew0) & .52 & .35 & .47 & .43 & .39 & 1.00 & & & & & \\
\hline 5 & Citations (Inskew0) & 1.15 & .66 & -.07 & -.06 & -.16 & -.25 & 1.00 & & & & \\
\hline 6 & Pages (Inskew0) & 2.87 & .35 & .04 & .03 & .07 & .01 & .08 & 1.00 & & & \\
\hline 7 & Journal Impact & 2.72 & .94 & .07 & .08 & .01 & .04 & .27 & -.21 & 1.00 & & \\
\hline 8 & Research Output (Inskew0) & 1.32 & 1.22 & .32 & .30 & .56 & .56 & .07 & .19 & .49 & 1.00 & \\
\hline 9 & Entry Year & 2001.54 & 3.33 & -.15 & -.13 & .53 & -.36 & .06 & .05 & -.07 & .15 & 1.00 \\
\hline
\end{tabular}

$N=5794$.

Inskew 0 indicates the zero-skewness logarithm of a variables, i.e., the variable is added with the constant one so that the logarithm can be also taken from values of zero. 
Table A2: Determinants of (editorial) board membership by splitting by entry year

\begin{tabular}{|c|c|c|c|c|c|c|c|}
\hline & \multirow[b]{2}{*}{ Entry Year } & \multicolumn{3}{|c|}{ Board Membership } & \multicolumn{3}{|c|}{ Editor Board Membership } \\
\hline & & B & S.E. & Sig. & B & S.E. & Sig. \\
\hline Publication record (Inskew0) & 1997 & 8.03 & 2.17 & $* * *$ & 8.96 & 2.21 & $* * *$ \\
\hline Publication record (Inskew0) ${ }^{2}$ & & -6.04 & 1.65 & $* * *$ & -6.16 & 1.70 & $* * *$ \\
\hline Control variables included & & YES & & & YES & & \\
\hline Publication record (Inskew0) & 1998 & 14.74 & 3.47 & $* * *$ & 12.97 & 3.49 & $* * *$ \\
\hline Publication record (Inskew0) ${ }^{2}$ & & -10.13 & 3.35 & $* * *$ & -8.39 & 3.49 & $* * *$ \\
\hline Control variables included & & YES & & & YES & & \\
\hline Publication record (Inskew0) & 1999 & 11.16 & 2.67 & $* * *$ & 12.89 & 2.61 & $* * *$ \\
\hline Publication record (Inskew0) ${ }^{2}$ & & -7.05 & 2.43 & $* * *$ & -8.93 & 2.40 & $*$ \\
\hline Control variables included & & YES & & & YES & & \\
\hline Publication record (Inskew0) & 2000 & 16.23 & 4.74 & $* * *$ & 16.47 & 4.96 & $* * *$ \\
\hline Publication record (Inskew0) ${ }^{2}$ & & -12.55 & 5.67 & * & -11.31 & 6.24 & $\dagger$ \\
\hline Control variables included & & YES & & & YES & & \\
\hline Publication record (Inskew0) & 2001 & 7.19 & 4.14 & $\dagger$ & 5.84 & 4.00 & \\
\hline Publication record (Inskew0) ${ }^{2}$ & & -7.23 & 4.54 & & -5.35 & 4.46 & \\
\hline Control variables included & & YES & & & YES & & \\
\hline Publication record (Inskew0) & 2002 & 15.39 & 5.76 & $* * *$ & 15.36 & 5.40 & $* * *$ \\
\hline Publication record (Inskew0) ${ }^{2}$ & & -12.46 & 6.73 & $\dagger$ & -12.62 & 6.41 & $*$ \\
\hline Control variables included & & YES & & & YES & & \\
\hline Publication record (Inskew0) & 2003 & 8.53 & 3.76 & $*$ & 8.32 & 3.70 & $*$ \\
\hline Publication record (Inskew0) ${ }^{2}$ & & -6.41 & 3.88 & $\dagger$ & -6.28 & 3.90 & \\
\hline Control variables included & & YES & & & YES & & \\
\hline Publication record (Inskew0) & 2004 & 4.68 & 5.74 & & 5.01 & 5.58 & \\
\hline Publication record (Inskew0)2 & & -.03 & 6.14 & & -.66 & 5.98 & \\
\hline Control variables included & & YES & & & YES & & \\
\hline Publication record (Inskew0) & 2005 & 25.05 & 7.62 & $* * *$ & 26.49 & 7.72 & $* * *$ \\
\hline Publication record (Inskew0) ${ }^{2}$ & & -20.57 & 7.90 & $* * *$ & -21.58 & 8.02 & $* *$ \\
\hline Control variables included & & YES & & & YES & & \\
\hline Publication record (Inskew0) & 2006 & 12.64 & 11.41 & & 8.47 & 10.37 & \\
\hline Publication record (Inskew0) ${ }^{2}$ & & -8.67 & 9.44 & & -4.50 & 8.50 & \\
\hline Control variables included & & YES & & & YES & & \\
\hline Publication record (Inskew0) & 2007 & -160.65 & 301921 & & 164.40 & 255103 & \\
\hline Publication record (Inskew0) ${ }^{2}$ & & 63.11 & 162184 & & -93.17 & 142375 & \\
\hline Control variables included & & YES & & & YES & & \\
\hline
\end{tabular}

$\dagger p<0.10,{ }^{*} p<0.05,{ }^{* *} p<0.01,{ }^{* * *} p<0.001$.

Inskew 0 indicates the zero-skewness logarithm of a variables, i.e. the variable is transformed so that the logarithm can be also taken from values of zero.

We included the control variables of Tables 3 and 4. 
Table A3: Change in AMJ board membership before and after 2009

\begin{tabular}{|c|c|c|c|c|}
\hline & & \multicolumn{2}{|c|}{ Board Membership before 2009} & \multirow[t]{2}{*}{ Total } \\
\hline & & No & Yes & \\
\hline \multirow[t]{2}{*}{ Board Membership 2009} & No & 945 & 47 & 992 \\
\hline & Yes & 73 & 78 & 151 \\
\hline Total & & 1018 & 125 & 1143 \\
\hline
\end{tabular}

Table A4: Determinants of AMJ board membership 2009

\begin{tabular}{|c|c|c|c|c|c|c|}
\hline & \multicolumn{3}{|c|}{ with former Board Members } & \multicolumn{3}{|c|}{ without former Board Member } \\
\hline & Coef. & SD & Sig. & Coef. & SD & Sig. \\
\hline (Constant) & -34.24 & 115.30 & & -23.67 & 115.95 & \\
\hline Publication record (Inskew0) & 3.43 & 1.93 & $\dagger$ & 3.61 & 1.73 & * \\
\hline Publication record (Inskew0) ${ }^{2}$ & -2.20 & 1.05 & * & -2.26 & 1.15 & * \\
\hline Control variables included & YES & & & YES & & \\
\hline Pseudo R-Square & & .1181 & & & .1350 & \\
\hline Log likelihood & & -723 & & & -713 & \\
\hline$N$ & & 1,102 & & & 1,102 & \\
\hline
\end{tabular}

$+p<0.10,{ }^{*} p<0.05,{ }^{* *} p<0.01,{ }^{* * *} p<0.001$.

Inskew 0 indicates the zero-skewness logarithm of a variables, i.e., the variable is transformed so that the logarithm can be also taken from values of zero.

We included the control variables of Tables 3 and 4 .

Table A5: Relatedness of the included journals according to cross-authorship

\begin{tabular}{lrrrrrrrrrrr}
\hline \multicolumn{1}{c}{ Percentage of authors of each journal having articles in other journals of the sample (column-wise) } \\
& AMJ & AMR & ASQ & BJM & JIBS & JM & JMST & JOB & OrSc & OrSt & SMJ \\
\hline AMJ & $100 \%$ & $44 \%$ & $35 \%$ & $6 \%$ & $16 \%$ & $42 \%$ & $15 \%$ & $21 \%$ & $25 \%$ & $12 \%$ & $26 \%$ \\
AMR & $16 \%$ & $100 \%$ & $12 \%$ & $7 \%$ & $6 \%$ & $16 \%$ & $12 \%$ & $9 \%$ & $15 \%$ & $9 \%$ & $8 \%$ \\
ASQ & $11 \%$ & $10 \%$ & $100 \%$ & $1 \%$ & $1 \%$ & $2 \%$ & $2 \%$ & $2 \%$ & $13 \%$ & $4 \%$ & $7 \%$ \\
BJM & $1 \%$ & $4 \%$ & $1 \%$ & $100 \%$ & $2 \%$ & $1 \%$ & $11 \%$ & $1 \%$ & $2 \%$ & $10 \%$ & $1 \%$ \\
JIBS & $13 \%$ & $13 \%$ & $4 \%$ & $10 \%$ & $100 \%$ & $13 \%$ & $14 \%$ & $3 \%$ & $13 \%$ & $8 \%$ & $17 \%$ \\
JM & $24 \%$ & $25 \%$ & $4 \%$ & $4 \%$ & $9 \%$ & $100 \%$ & $12 \%$ & $19 \%$ & $7 \%$ & $3 \%$ & $14 \%$ \\
JMST & $8 \%$ & $18 \%$ & $3 \%$ & $31 \%$ & $10 \%$ & $11 \%$ & $100 \%$ & $3 \%$ & $10 \%$ & $28 \%$ & $8 \%$ \\
JOB & $19 \%$ & $20 \%$ & $6 \%$ & $6 \%$ & $3 \%$ & $29 \%$ & $5 \%$ & $100 \%$ & $7 \%$ & $3 \%$ & $3 \%$ \\
OrSC & $14 \%$ & $22 \%$ & $25 \%$ & $6 \%$ & $9 \%$ & $7 \%$ & $10 \%$ & $5 \%$ & $100 \%$ & $14 \%$ & $13 \%$ \\
OrSt & $6 \%$ & $12 \%$ & $7 \%$ & $25 \%$ & $5 \%$ & $2 \%$ & $24 \%$ & $2 \%$ & $12 \%$ & $100 \%$ & $4 \%$ \\
SMJ & $33 \%$ & $28 \%$ & $30 \%$ & $9 \%$ & $27 \%$ & $32 \%$ & $18 \%$ & $4 \%$ & $29 \%$ & $10 \%$ & $100 \%$ \\
\hline
\end{tabular}

$T=1997-2007, N=5,794$ authors with 5,509 articles.

Reading example: $16 \%$ of the authors publishing in AMJ have also an article in AMR, but $44 \%$ of the authors publishing in AMR have also an article in AMJ. 


\section{Table A6: Relatedness of the included journals according to cross-editorship}

\begin{tabular}{lrrrrrrrrrrr}
\hline \multicolumn{7}{c}{ Percentage of editors of each journal having editor positions in other journals of the sample (column-wise) } \\
& AMJ & AMR & ASQ & BJM & JIBS & JM & JMST & JOB & OrSc & OrSt & SM J \\
\hline AMJ & $100 \%$ & $24 \%$ & $16 \%$ & $7 \%$ & $11 \%$ & $14 \%$ & $11 \%$ & $9 \%$ & $7 \%$ & $7 \%$ & $18 \%$ \\
AMR & $22 \%$ & $100 \%$ & $18 \%$ & $7 \%$ & $3 \%$ & $12 \%$ & $10 \%$ & $6 \%$ & $9 \%$ & $8 \%$ & $11 \%$ \\
ASQ & $8 \%$ & $10 \%$ & $100 \%$ & $2 \%$ & $3 \%$ & $4 \%$ & $2 \%$ & $2 \%$ & $16 \%$ & $5 \%$ & $6 \%$ \\
BJM & $3 \%$ & $3 \%$ & $1 \%$ & $100 \%$ & $2 \%$ & $6 \%$ & $3 \%$ & $3 \%$ & $1 \%$ & $1 \%$ & $2 \%$ \\
JIBS & $13 \%$ & $4 \%$ & $6 \%$ & $7 \%$ & $100 \%$ & $6 \%$ & $12 \%$ & $4 \%$ & $6 \%$ & $4 \%$ & $17 \%$ \\
JM & $9 \%$ & $9 \%$ & $5 \%$ & $10 \%$ & $3 \%$ & $100 \%$ & $7 \%$ & $10 \%$ & $7 \%$ & $2 \%$ & $5 \%$ \\
JMST & $16 \%$ & $16 \%$ & $6 \%$ & $12 \%$ & $15 \%$ & $15 \%$ & $100 \%$ & $6 \%$ & $9 \%$ & $23 \%$ & $16 \%$ \\
JOB & $11 \%$ & $9 \%$ & $5 \%$ & $10 \%$ & $4 \%$ & $20 \%$ & $5 \%$ & $100 \%$ & $4 \%$ & $5 \%$ & $5 \%$ \\
OrSC & $3 \%$ & $4 \%$ & $14 \%$ & $2 \%$ & $2 \%$ & $5 \%$ & $3 \%$ & $2 \%$ & $100 \%$ & $5 \%$ & $6 \%$ \\
OrSt & $7 \%$ & $9 \%$ & $9 \%$ & $2 \%$ & $3 \%$ & $3 \%$ & $16 \%$ & $4 \%$ & $12 \%$ & $100 \%$ & $5 \%$ \\
SMJ & $26 \%$ & $17 \%$ & $17 \%$ & $7 \%$ & $21 \%$ & $11 \%$ & $16 \%$ & $6 \%$ & $20 \%$ & $8 \%$ & $100 \%$ \\
\hline
\end{tabular}

$T=2009, N=1,181$ editors.

Reading example: $22 \%$ of the editorial board members of AMJ are also editorial board members in AMR, but $24 \%$ of the editor board members of AMR are also editor board members in AMJ.

\section{References}

Adler, Nancy J. and Anne-Wil Harzing (2009), When Knowledge Wins: Transcending the Sense and Nonsense of Academic Rankings, Academy of Management Learning \& Education 8, 72-95.

Adler, Robert, John Ewing, and Peter Taylor (2008), Citation Statistics, A Report from the Joint Committee on Quantitative Assessment of Research (IMU, ICIAM, IMS).

Albers, Sönke (2009), Three Failed Attempts of Joint Rankings of Research in Economics and Business, German Economic Review 10, 352-363.

Baccini, Alberto and Lucio Barabesi (2008), Interlocking Editorship: A Network Analysis of the Links between Economic Journals, Social Science Research Network (SSRN).

Banerjee, Abhijit V. (1992), A Simple Model of Herd Behavior, Quarterly Journal of Economics 107, 797-817.

Barabási, Albert-László and Réka Albert (1999), Emergence of scaling in random networks, Science 286, 509-512.

Beed, Clive and Clara Beed (1996), Measuring the quality of academic journals: The case of economics, Journal of Post Keynesian Economics 18, 369-396.

Bell, John G. and John J. Seater (1978), Publishing Performance: Departmental and Individual, Economic Inquiry 16, 599-615.

Bikhchandani, Sushil, David Hirshleifer, and Ivo Welch (1992), A Theory of Fads, Fashion, Custom, and Cultural Change as Informational Cascades, Journal of Political Economy 100, 992-1026.

Bommer, Rolf and Heinrich W. Ursprung (1998), Spieglein, Spieglein an der Wand: Eine Publikationsanalytische Erfassung der Forschungsleistungen volkswirtschaftlicher Fachbereiche in Deutschland, Osterreich und der Schweiz, Zeitschrift für Wirtschafts- und Sozialwissenschaften 118, 1-28.

Bonitz, Manfred, Eberhard Bruckner, and Andrea Scharnhorst (1999), The Matthew Index - Concentration patterns and Matthew core journals, Scientometrics 44, 361-378.

Borgman, Christine L. (1990), Scholarly communication and bibliometrics, Newbury Park: Sage. 


\section{K. ROST/B. S. FREY}

Borgman, Christine L. and Jonathan Furner (2002), Scholarly communication and bibliometrics, Annual Review of Information Science and Technology 36, 3-72.

Bräuninger, Michael and Justus Haucap (2003), Reputation and Relevance of Economics Journals, Kyklos 56, 175-198.

Butler, Linda (2003), Explaining Australia’s increased share of ISI publications - the effects of a funding formula based on publication counts, Research Policy 32, 143-155.

Chamley, Christophe and Douglas Gale (1994), Information revelation and strategic delay in a model of investment, Econometrica 62, 1065-1085.

Cheng, Chun Hung, Clyde W. Holsapple, and Anita Lee (1995), Citation-based journal rankings for expert system research, Expert Systems 12, 313-322.

Cherchye, Laurens and Pierre Vanden Abeele (2005), On research efficiency - A micro-analysis of dutch university research in economics and business management, Research Policy 34, 495-516.

Coats, Alfred William (1971), The Role of Scholarly Journals in the History of Economics: An Essay, Journal of Economic Literature 9, 29-44.

Cole, Stephen (1992), Making Science. Between Nature and Society, Cambridge: Harvard University Press.

Council for the Humanities Arts and Social Sciences (2005), Measures of Quality and Impact of Publicly Funded Research in the Humanities, Arts and Social Sciences. Occasional Paper 2, http://www.chass.org.au/op2.pdf.

Coupé, Tom (2003), Revealed Performances: Worldwide Rankings of Economists and Economics Departments, 1990 - 2000, Journal of the European Economic Association 1, 1309-1345.

Cronin, Blaise (1996), Rates of return to citation, Journal of Documentation 52, 188-197.

Cronin, Blaise and Lokman I. Meho (2008), The shifting balance of intellectual trade in information studies, Journal of the American Society for Information Science and Technology 59, 551-564.

Dasgupta, Partha and Paul A. David (1994), Towards a new economics of science, Research Policy 23, 487-521.

Diamond, Arthur M. (1986), What is a citation worth?, Journal of Human Resources 21, 200-215.

Diamond, Arthur M. (1989), The Core Journals in Economics, Current Contents 1, 4-11.

Donovan, Claire (2006), The Chequered Career of a Cryptic Concept, The Political Quarterly 77, 61-72.

Donovan, Claire and Linda Butler (2007), Testing novel quantitative indicators of research 'quality', esteem and 'user engagement': an economics pilot study, Research Evaluation 16, 231-242.

Fabel, Oliver, Miriam Hein, and Robert Hofmeister (2008), Research Productivity in Business Economics: An Investigation of Austrian, German and Swiss Universities, German Economic Review 9, 506-531.

Faria, João Ricardo (2005), The game academics play: editors versus authors, Bulletin of Economic Research 57, 1-12.

Frey, Bruno S. (2003), Publishing as prostitution? - Choosing between one's own ideas and academic success, Public Choice 116, 205-223.

Frey, Bruno S. (2007), Evaluierungen, Evaluierungen ... Evaluitis, Perspektiven der Wirtschaftspolitik 8, 207-220.

Frey, Bruno S. (2010), Economists in the PITS?, International Review of Economics 56, 335-346.

Frey, Bruno S. and Katja Rost (2010), Do rankings reflect research quality?, Journal of Applied Economics 13, 1-38.

Garfield, Eugene (1979), Citation indexing: Its theory and application in science, technology, and humanities, New York: Wiley.

Garfield, Eugene (1997), Editors are justified in asking authors to cite equivalent references from same journal, British Medical Journal 314, 1765-1765.

Gibbons, Jean D. (1990), United-States institutional representations on editorial-boards of U.S. statistics journals, American Statistician 44, 210-213.

Gibbons, Jean D. and Mary Fish (1991), Ranking of economics faculties and representation on editorial-boards of top-journals, Journal of Economic Education 22, 361-372.

Gigerenzer, Gerd (2007), Gut feelings, New York: Penguin/Viking.

Gioia, Denis A. and Kevin G. Corley (2002), Being good versus looking good: Business school rankings and the circean transformation from substance to image, Academy of Management Learning and Education 1, 107-120. 
Gladwell, Malcolm (2005), Blink. The power of thinking without thinking, New York: Little, Brown, and Company.

Handelsblatt (2006), Economist Ranking, http://www.handelsblatt.com/politik/vwl-ranking/.

Handelsblatt (2007), Economist Ranking, http://www.handelsblatt.com/politik/vwl-ranking/.

Handelsblatt (2009), Handelsblatt-Ranking Betriebswirtschaftslehre (BWL), http://www.handelsblatt.com/politik/ bwl-ranking/bwl-ranking-methodik-und-interpretation;2175006.

Hennig-Thurau, Thorsten, Gianfranco Welsh, and Ulf Schrader (2004), VHB-JOURQUAL: Ein Ranking von betriebswirtschaftlich-relevanten Zeitschriften auf Grundlage von Expertenurteilen, zfbf 56, 520-545.

Henrekson, Magnus and Daniel Waldenstrom (2007), How should research performance be measured?, IFN Working Paper 712, 1-16.

Hofmeister, Robert and Heinrich W. Ursprung (2008), Das Handelsblatt Ökonomen-Ranking 2007: Eine kritische Beurteilung, Perspektiven der Wirtschaftspolitik 9, 254-266.

Holmström, Bengt and Paul Milgrom (1991), Multitask Principal-Agent Analyses: Incentice Contracts, Assert Ownership and Job Design, Journal of Law, Economics, and Organization 7(Special Issue), 24-52.

Horrobin, David F. (1990), The philosophical basis of peer review and the suppression of innovation, Journal of the American Medical Association 263, 1438-1441.

Johnes, Geraint (1988), Determinants of Research Output in Economics Departments in British Universities, Research Policy 17, 171-178.

Judge, Timothy A., Daniel M. Cable, Amy E. Colbert, and Sara L. Rynes (2007), What Causes a Management Article to be Cited - Article, Author, or Journal?, Academy of Management Journal 50, 491-506.

Katz, J. Sylvan (1999), Bibliometric Indicators and the Social Sciences. Report to the UK Economic and Social Research Council, SPRU, University of Sussex, http://www.sussex.ac.uk/Users/sylvank/pubs/ESRC.pdf.

Kaufman, George G. (1984), Rankings of finance departments by faculty representation on editorial boards of professional journals - a note, Journal of Finance 39, 1189-1197.

Kurtz, David L. and Louis E. Boone (1988), Rating marketing faculties on the basis of editorial review board memberships, Journal of Marketing Education 10, 64-68.

Laband, David N. and Michael J. Piette (1994), The relative impacts of economics journals - 1970-1990, Journal of Economic Literature 32, 640-666.

Lee, Frederic S. (2006), The ranking game, class and scholarship in American mainstream economics, Australasian Journal of Economics Education 3, 1-41.

Lee, Frederic S. (2008), A case for ranking heterodox journals and departments, On the Horizon 16, 241-251.

Liebowitz, Stan J. and John P. Palmer (1984), Assessing the relative impacts of economics journals, Journal of Economic Literature 22, 77-88.

Lo, Melody, M. C. Sunny Wong, and Franklin G. Mixon (2008), Ranking economics journals, economics departments, and economists using teaching-focused research productivity, Southern Economic Journal 74, 894-906.

Luwel, Marc, Henk F. Moed, Anton J. Nederhof, V. De Samblanx, K. Verbrugghen, and L. J. van der Wurff (1999), Towards Indicators of Research Performance in the Social Sciences and Humanities, CWTS Leiden.

Meho, Lokman I. (2007), The rise and rise of citation analysis, Physics World 20, 32-36.

Meho, Lokman I. and Yvonne Rogers (2008), Citation counting, citation ranking, and h-Index of human-computer interaction researchers: a comparison of Scopus and Web of Science, Journal of the American Society for Information Science and Technology 59, 1711-1726.

Merton, Robert K. (1968), The Matthew Effect in Science, Science 159, 56-63.

Moed, Henk F. (2005), Citation analysis in research evaluation, Dordrecht: Springer.

Moed, Henk F., W. J. M. Burger, J. G. Frankfort, and Anthony F. J. Van Raan (1985), The use of bibliometric data for the measurement of university research performance, Research Policy 14, 131-149.

Moxham, H. and J. Anderson (1992), Peer review. A view from the inside, Science and Technology Policy 5, 7-15 


\section{K. ROST/B. S. FREY}

Nederhof, A. J. and Anthony F. J. van Raan (1993), A bibliometric analysis of six economics research groups: A comparison with peer review, Research Policy 22, 353-368.

Nelson, Richard R. (2004), The market economy, and the scientific commons, Research Policy 33, 455-471.

Nightingale, Paul and Alister Scott (2007), Peer review and the relevance gap: ten suggestions for policy-makers, Science and Public Policy 34, 543-553.

Osterloh, Margit and Bruno S. Frey (2008), Anreize im Wissenschaftssystem, Working Paper, CREMA - Center for Research in Economics, Management and the Arts, Switzerland.

Osterloh, Margit and Bruno S. Frey (2009), Are more and better indicators the solution? Comment to William Starbuck, Scandinavian Journal of Management 25, 225-227.

Osterloh, Margit and Bruno S. Frey (2010), Academic Rankings and Research Governance, Working Paper, CREMA - Center for Research in Economics, Management and the Arts, Switzerland.

Paul, Karen (2004), Business and society and business ethics journals: A citation and impact analysis, Journal of Scholarly Publishing 35, 103-117.

Perry-Smith, Jill E. and Christina E. Shalley (2003), The social side of creativity: A static and dynamic social network perspective, Academy of Management Review 28, 89-106.

Podsakoff, Philip M., Scott B. Mackenzie, Daniel G. Bachrach, and Nathan P. Podsakoff (2005), The influence of management journals in the 1980s and 1990s, Strategic Management Journal 26, 473-488.

Prendergast, Canice (1999), The Provision of Incentives in Firms, Journal of Economic Literature 37, 7-63.

Reedijk, Jan (1998), Sense and nonsense of science citation analyses: comments on the monopoly position of ISI and citation inaccuracies. Risks of possible misuse and biased citation and impact data, New Journal of Chemistry 22, 767-770.

Rigby, John and Jakob Edler (2005), Peering inside research networks: Some observations on the effect of the intensity of collaboration on the variability of research quality, Research Policy 34, 784-794.

Schrader, Ulf and Thorsten Hennig-Thurau (2009), VHB-JOURQUAL2: Method, Results, and Implications of the German Academic Association for Business Research's Journal Ranking, BuR-Business Research 2, 180-204.

Seglen, Per O. (1994), Causal Relationship between Article Citedness and Journal Impact, Journal of the American Society for Information Science 45, 1-11.

Seglen, Per O. (1997), Why the impact factor of journals should not be used for evaluating research, British Medical Journal 314, 498-502.

Simkin, Mikhail V. and Vwani P. Roychowdhury (2005), Stochastic modeling of citation slips, Scientometrics 62, 367-384.

Simkin, Mikhail V. and Vwani P. Roychowdhury (2006), Do you sincerely want to be cited? Or: read before you cite, Significance 12, 179-181.

Simkin, Mikhail V. and Vwani P. Roychowdhury (2007), A mathematical theory of citing, Journal of the American Society for Information Science and Technology 58, 1661-1673.

Singh, Gangaram, Kamal M. Haddad, and Chee W. Chow (2007), Are articles in “Top” management journals necessarily of higher quality?, Journal of Management Inquiry 16, 319-331.

Small, Henry (1999), Visualizing science by citation mapping, Journal of the American Society for Information Science 50, 799-813.

Sombatsompop, Narongrit, Teerasak Markpin, and N. Premkamolnetr (2004), A modified method for calculating the Impact Factors of journals in ISI Journal Citation Reports: Polymer Science Category in 1997-2001, Scientometrics 60, 217-235.

Starbuck, William H. (2009), The constant causes of never-ending faddishness in the behavioral and social sciences, Scandinavian Journal of Management 25, 108-116.

The Thomson Corporation (2008), ISI Web of Knowledge Journal Citation Report, http://admin-apps.isiknowledge. com/JCR/. 
van Raan, Anthony F. J. (2003), The use of bibliometric analysis in research performance assessment and monitoring of interdisciplinary scientific developments, Technikfolgenabschätzung 1, 20-29.

Warner, Julian (2000), A critical review of the application of citation studies to the Research Assessment Exercises, Journal of Information Science 26, 453-459.

Weingart, Peter (2005), Impact of bibliometrics upon the science system: Inadvertent consequences?, Scientometrics 62, 117-131.

White, Howard D. and Katherine W. McCain (1998), Visualizing a discipline: An author co-citation analysis of information science, 1972-1995, Journal of the American Society for Information Science 49, 327-355.

Wirtschaftsuniversität Wien (2008), WU-Journal-Rating: http://bach.wu-wien.ac.at/fides/res/WU_Journal_Rating_2008.pdf. 